\title{
DA CONSTRUÇÃO DO SOCIALISMO AO PROCESSO DE REUNIFICAÇĀO E PRIVATIZAÇĀO NA ALEMANHA ORIENTAL
}

\author{
Renato Kilpp \\ Tudo o que é sólido desmancha no ar: \\ K.Marx
}

\section{A CONSTRUGĀO DO SOCIALISMO NA ALEMANHA ORIENTAL}

A expansão territorial do socialismo foi resultado exclusivo da correlação de forças internacionais no imediato pós-guerra. A URSS, enquanto força aliada contra o nazismo, teve direitos especiais sobre os territórios ocupados e habilitou-se a participar da nova organização, administração e controle da nova geografia política mundial, no intuito de um processo de desmilitarização e desnazificação da Alemanha e da Europa ocupada.

A Alemanha oriental pode ser o mais rico exemplo da negligência teórica da revolução socialista associada às então modernas e estalinistas teses da evolução do socialismo no sentido do expansionismo soviético

Como nos demais exemplos históricos, o socialismo na Alemanha oriental não surge das contradições entre forças produtivas e relações de produção, tão pouco tenı características politico-revolucionárias de base social. Os seus determinantes foram exclusivamente extemos e o apoio intemo é inicialmente figurativo, resultando da incapacidade moral, politica e ideológica de propor altemativas elou resistir aos novos poderes que estabelecem-se exogenamente.

Professor do Mestrado em Economia, UFPB, Campus I!. Doutorando em Economia, Universidade Livre de Berlim, Alemanha.

Rev. Raizes, Campina Grande, Ano XV. "n II, pp. 103-130, Junho 1995 
Sempre foi evidente - e não exclusivamente para os representantes das forças ocidentais - que o interesse soviético ultrapassava os estreitos limites de uma simples desmilitarização e "desnazificação" da região sob seu controle. Tão pouco os interesses nas indenizações de guerra esgotariam as perspectivas soviéticas para o setor oriental alemão. A intenção soviética, conhecida por um pequeno grupo de dirigentes comunistas alemães, era a instalação do modelo soviético em território alemão. Somente assim, afirmavam os dirigentes soviéticos, seria possível destruir o fascismo e o militarismo alemão. ${ }^{1}$

Desde a proclamação de Truman-Doktrin e do Plano Marshall em 1947 estava determinada, para os russos, uma situação irreversível de confronto. $\mathrm{O}$ imperialismo americano mostrara suas reais intenções. Por outro lado, a eliminação dos parceiros civis do governo de Praga em fevereiro de 1948 exteriorizava os interesses soviéticos no controle político do leste europeu.

Após a $2^{\mathrm{a}}$ Conferência de Londres, é anunciada uma reforma monetária exclusiva para o setor ocidental e em junho de 1948 é criada uma nova moeda. Segundo as análises soviéticas e de seus aliados alemães, os EUA tencionavam interferir-controlar a economia oriental a partir da circulação monetária. Em represália os soviéticos fecharam as fronteiras e cancelaram o fornecimento de água, luz e gás para Berlimocidental. Paralelamente também promoveram uma reforma monetária. A realidade de duas moedas distintas caracterizou a existência de dois estados independentes, embora ainda formalmente unidos.

Os poderes ocidentais determinaram em julho de 1948 o início dos trabalhos para a formação de uma Constituição para a Alemanha Ocidental. $\mathrm{Na}$ área de ocupação soviética as lideranças fecharam um plano bienal (1949-50)) e simultaneamente informaram a unificação dos partidos em um partido de tipo novo, baseado no modelo do partido co-

1 "Ein 'Fernzil' der UdSSR bestand 1945 auch darin, in Deutschland ihr eigenes System zu installieren. Nur dadurch glaubte sie 'Faschismus und Militarismus' endgueltig austotten zu koennen, diee ja nach der sowjetischen Ideologie Folgen des Kapitalismus und der buergerlichen Staatsreform, also auch des Parlamentarismus und seines Parteisystems, waren”. Hermann Weber, 1989. p. 50. 
munista soviético.

Em 07 de outubro de 1949 foi criada oficialmente a República Democrática da Alemanha. $O$ projeto socialista para a região de ocupação militar soviética conquista o status de política de Estado.

\section{A CAPACIDADE DO DESENVOLVIMENTO ECONÔMICO NA BASE DO ESTATISMO}

A destruição do parque industrial alemão foi relativamente grande durante o periodo de guerra. $21 \%$ das indústrias da região ocidental e $15 \%$ na região oriental. ${ }^{2}$ Não fossem os ressarcimentos cobrados por Stálin até sua morte em 1953, (os cálculos apontam para valores de até 100 bilhões de marcos em trilhos de estradas de ferro, indústrias eletrônicas, químicas, têxteis, sapatos, energia, etc., transferidos para território soviético), a Alemanha Oriental teria tido boas condições de recuperação econômica, mesmo considerando que em seu parque industrial original não predominava a indústria de base mas a indústria de bens de consumo.

$\mathrm{Na}$ agricultura, as mudanças são mais rápidas e radicais. A reforma agrária representou o início do processo da desapropriação/socialização da zona sob controle soviético. Realizada ainda em 1945 , todas as propriedades com mais de $100 \mathrm{Ha}$ são estatizadas e todos os grandes proprietários de terras, considerados criminosos de guerra, desapropriados sem indenizações. Transformados nos históricos vilões das crises e guerras, foi relativamente simples promover a reforma agrária na Alemanha oriental. ${ }^{3}$

${ }^{2}$ Segundo Christ e Neubauer, "der Krieg hatte im Osten deutlich geringere Spuren der Verwüstung hinterlassen. Nur etwa 15\% des industriellen Potentials war zerstört. In den Westzonen lag die Schadenskoste dagegen 21\%" (Christ/Neubauer, 1991, p. 18).

${ }^{3}$ Segundo Grotewohl, Presidente do SPD em 1945, "Die politische Seite der Bodenreform ist die Beseitigung des Verderblichen Einflusses der Junker auf die Geschicke Deutschlands. Durch Jahrhunderte war der Großgrundbesitzer der Träger der Reaktion. Aus ihren Reihen stammen zahlreiche hohe Offiziere, Beamte, Minister und Höfliche. Sie waren die Feinde jeder Freiheitlichen Entwicklung in 
Em janeiro de 1946 o KPD ${ }^{4}$ definiu as linhas de reconstrução da economia alemã fundamentando-se na expropriação das empresas pertencentes a criminosos de guerra. Segundo estas novas diretrizes, todas as indústrias e empresas de comércio, de transportes e seguros de propriedade de nazistas, de seus aliados ou simpatizantes seriam transferidas para organismos estatais.

Ainda em 1946, o recém criado $S_{E D}^{5}$ e a $S M A D^{6}$ promoveram um plebiscito para legitimar a estatização das indústrias no estado de Sachsen. Novamente a medida é sustentada na punição dos criminosos de guerra e fascistas ativos. Somente em Sachsen 1.900 empresários foram desapropriados sem indenizações. Outras 1.800 empresas foram estatizadas sem que a direção do SED ou a administração soviética na Alemanha oriental sentisse necessidade de legitimar a medida perante a sociedade. Os resultados do plebiscito de Sachsen $(77,6 \%$ de apoio às medidas de desapropriação) foram considerados suficientes para legitimar a medida em ampla escala e estende-la para o restante do setor oriental. Com isso elevou-se o número global das propriedades coletivas além de 3.800. Juntamente com as sociedades acionárias soviéticas, a propriedade estatal na Alemanha oriental responsabilizava-se já em 1947 por $60 \%$ da produção industrial. Em 1952 o estado já garantia $90 \%$ da produção industrial global. ${ }^{7}$ Concluída a tarefa da estatização, restava a tarefa de coordenar a produção e o desenvolvimento.

As experiências históricas do socialismo buscaram comprovar que a lógica capitalista seria a fonte das guerras, do desemprego, da miséria, do desabastecimento, das crises, da má distribuição de renda e de todas as mazelas humanas. $\mathrm{O}$ fundamento deste discurso representava a negação dialética do capitalismo e se pretendia enquanto sua superação

Deutschland". In Weber, 1989, p. 111.

${ }^{4}$ KPD-Kommunistische Partei Deutschlands. Partido Comunista da Alemanha.

${ }^{5}$ SED-Sozialistiche Einheitspartei Deutschlands. Partido da Unidade Socialista da Alemanha.

${ }^{6}$ SMAD-Sowjetische Militäradministration in Deutschland. (Administração Militar Soviética na Alemanha).

${ }^{7}$ Vide, Christ und Neubauer, 1991. 
histórica. Um novo modelo, no qual o Homem e suas necessidades representassem a nova qualidade da vida e da existência humana.

A URSS e os demais países socialistas ulteriores à revolução de outubro depararam-se com os limites históricos da organizaçãoconstituição prática do socialismo. Tantos os dilemas políticos (país socialista isolado na lógica mundial capitalista), quanto os econômicos (produção e produtividade) e os sociais (o indivíduo submetido à lógica do coletivo, perdendo suas características próprias, suas particularidades) representaram na história a necessidade da formação/constituição da categoria socialismo real, cuja finalidade seria justificar as contradições concretas da realidade socialista. Os limites históricos do socialismo real se expressaram na negação do socialismo científico, especialmente quando confrontado com a ainda inegável capacidade progressiva (mesmo enquanto processo destrutivo) do capitalismo.

O problema do socialismo não foi somente uma derivação de leituras equivocadas, maniqueístas ou ideológicas. A chamada ditadura do proletariado representou de fato, na história, a própria contradição não-dialética do socialismo. Uma contradição que, para materializar-se em progresso histórico, necessitaria ser dialeticamente superada.

O denominado "interesse coletivo" anulou os indivíduos como sujeitos indivíduos e impôs um conjunto de limites históricos à reprodução e evolução progressiva da sociedade. Esta afirmação não implica na negação absoluta do socialismo no que refere-se ao conteúdo social básico. $\mathrm{O}$ socialismo real representou conquistas sociais importantes. Escolas, saúde, trabalho, habitação... Não considerou, no entanto, a humanidade na sua evolução natural de desenvolvimento progressivo de necessidades sociais, incluindo-se as relativas ao individuo enquanto tal e não simplesmente como membro do coletivo. Esqueceram-se dos conflitos individuais, do amor, da felicidade, do prazer, do sexo, da família, dos amigos, da cultura, da arte, da natureza (humana e natural), das crises profissionais ou existenciais, das raças (enquanto cultura-identidade), dos cultos místicos ou da religião oficial.

Entre o socialismo de resultados, que atende a reprodução material do corpo, e o socialismo científico, que objetiva a realização do 
Homem, estabeleceu-se uma lacuna geográfica, política e historicamente insuperável. A falta das liberdades democráticas associada à escassez de vários produtos básicos e dos produtos de tecnologia de ponta transformaram-se nos catalisadores da crise definitiva. A negação da teoria socialista deu-se contudo numa dimensão empírica sem correspondência teórica.

\section{OS LIMITES DO PROGRESSO: A BUROCRACIA COMO OBSTÁCULO}

O problema do burocratismo na RDA foi discutido secretamente pelos membros do Comitê Central do SED já em 1955. Havia um consenso cúmplice entre os membros do Partido sobre os excessos de centralismo e de burocratismo. No entanto, a base do poder absoluto, da dominação, estavam fundamentadas neste tipo de organização estatal e não haviam altemativas possíveis à manutenção-reprodução da dominação legal sem o controle absoluto de todas as instâncias do poder. $O$ custo da incompetência, da falta de produtividade, da insegurança na tomada de decisões simples, do desgaste dos principais dirigentes com detalhes do cotidiano administrativo, etc., resultaram na contradição da efetivação do progresso e conquistas sociais significativas com sua própria legitimação. A alternativa da descentralização e desburocratização resultaria no enfraquecimento do poder do Partido - e possivelmente do próprio socialismo -, enquanto que a alternativa inversa, embora sustente o poder político, tem na força e no terror seu principal fundamento.

Mesmo consideradas as incompetências do centralismo absoluto e do burocratismo exagerado, explicitadas em muitos exemplos expostos pelos próprios membros do Comitê Central do SED, não foram consideradas alternativas significativas que alterassem o tipo de Estado necessário à manutenção do regime socialista imposto pela União Soviética.

Entre os aliados socialistas, a Alemanha oriental foi um país exemplar. Destruída na guerra, conseguiu transformar-se na potência do oriente sem os auxílios que os alemães do ocidente haviam recebido 
dos antigos adversários de combate. Os padrões de produção e produtividade foram relativamente altos e garantiram uma qualidade de vida regular aos cidadãos da RDA.

O progresso é contudo relativo. O lebensstandard obtido na RDA foi exemplar ao mundo socialista, mas sempre que os referenciais voltavam-se para a qualidade da vida nos paises da Europa ocidental, surgia como modelo estagnado e repressivo. Comparações entre as duas Alemanhas sempre foram realizadas com finalidades políticasideológicas de demonstração do potencial produtivo das economias capitalistas frente as socialistas. Os alemães orientais não deixavam de venerar as maravilhas consumistas dos compatriotas, suas liberdades democráticas e de trânsito.

A necessidade inicial da centralização tornou-se rapidamente fundamento de uma burocratização que contaminou todos os paralelos da sociedade alemã oriental. A economia foi estruturada em combinados vertical e horizontalmente integrados, caracterizando um monopólio absoluto dos setores produtivos, que não tinham, por sua vez, autonomia na definição de sua própria estrutura produtiva. A centralização de todo o sistema fazia do partido (SED) o fundamento determinante e presente em todos os setores da economia, desde os conselhos de ministros até os comitês de fábrica, compostos, evidentemente, por membros do partido. A estrutura econômica da RDA era composta basicamente por 152 monopólios combinados, integrados tanto vertical quanto horizontalmente. A agricultura organizava-se por meio de cooperativas de produção (Landwirtschaftlichen Produktionsgenossenschaften - LPG) e - comércio através da central de organização do comércio (Handelsorganisation - HO) e das cooperativas de consumo (Konsumgenossenschaft).

A integração com o mercado internacional era também relativamente baixa, predominando o comércio na esfera dos paises integrantes do COMECON. Este seria também um dos fundamentos a impedir que a concorrência atuasse de forma a impulsionar a produtividade socialista, na medida em que o comércio exterior entre os países socialistas baseava-se em acordos de solidariedade ideológica e não de ganhos diferenciais. A RDA fornecia máquinas, equipamentos, navios e vagões 
de trens. Da URSS a RDA recebia matérias-primas como petróleo e gás natural, da Bulgária vinham uvas e tomates, da Hungria vinho, da Checoslováquia bondes elétricos, da Polônia carvão e material para a construção civil.

A contabilidade entre as nações socialistas era feita através de rublos transferiveis, que serviam somente como medida de valor dos escambos socialistas.

Organizada numa estrutura sem concorrência, os estímulos do desenvolvimento das forças produtivas eram nulos. Quando confrontadas com os paises capitalistas do ocidente, as economias socialistas resistiam artificialmente impondo taxas de câmbio irreais e elevadas taxas de importação, transformando as fronteiras territoriais em equivalente de taxas diferenciadas de produtividade. Era possivel negociar com o ocidente sem destruir as bases produtivas nacionais exclusivamente em função da existência destas fronteiras "niveladoras" da (im)produtividade.

Os limites da produção socialista foram sempre justificados pela distribuição. Produção socialista significa produção de interesse social, de atendimento das necessidades sociais básicas, das necessidades elementares da reprodução do corpo. Alimento básico, saúde básica, educação básica, habitação básica, trabalho básico... Necessidades que ultrapassassem estes denominados critérios básicos não eram prioritárias e careciam de recursos estatais para serem atendidas. Os produtos considerados supérfluos ou não contavam com investimentos do Estado ou não recebiam subsídios na comercialização, o que os tomava extremamente caros. Uma televisão preto e branco custava mais de 2 mil RDA-Marcos e um rádio ultrapassava facilmente a casa dos mil RDAMarcos. Sem a possibilidade de adquirir aparelhos modernos (e coloridos) ou aparelhos de som com Laser do ocidente, os alemães orientais obrigavam-se ao consumo do existente ao preço do absurdo.

A lógica da produção social também não permitia que outros determinantes do consumo interferissem ou na produção ou no próprio consumo. As fábricas têxteis, por exemplo, deviam produzir mercadorias de maneira relativamente uniforme, afim de evitar um consumo 
impulsivo, um consumo não imposto pela necessidade real do objeto. A uniformidade dos casacos de inverno, sem variações nos modelos e cores, não estimulava o consumo supérfluo e permitia que uma produção limitada atendesse o mercado necessário. As fábricas de automóveis produziam dois modelos em meia dúzia de cores. No caso dos automóveis não haveria sequer o estímulo da moda, pois se aguardava em média 12 anos para obter o carro encomendado: Trabant ou Wartburg, produzidos na própria RDA ou ainda Ladas da URSS ou Skodas da Checoslováquia - estes últimos reservados a "consumidores especiais". As fábricas óticas ou de sapatos seguiam as mesmas regras do consumo prioritário e necessário do ponto de vista básico e não do consumo impulsivo, próprio das sociedades ocidentais.

A concepção limitada do conteúdo do termo necessidade produziu a negação do conteúdo do termo social, pois impunha padrões de consumo definidos burocraticamente em nome do coletivo. Um coletivo composto de individuos que tomam-se progressivamente insatisfeitos e perdem o interesse pelo cotidiano padronizado. Novas necessidades, além das físicas, passam a representar o indivíduo e a insatisfação é crescente na proporção da impossibilidade de satisfação de novas necessidades. E algo como a teoria social da relatividade ou teoria relativa do bem-estar social: o padrão de vida de um alemão oriental foi um paraíso para um trabalhador de país subdesenvolvido, um inferno para um cidadão de país desenvolvido e um purgatório para os próprios alemães orientais.

O socialismo do leste europeu obteve tanto a glória da conquista da possibilidade da reprodução do corpo (mesmo que para tanto se enfrentassem filas quilométricas para consumir produtos básicos), quanto a irresponsabilidade de concluir sua história nesta tarefa básica. A construção da sociedade comunista, da sociedade do não-trabalho ou da sociedade do pós-trabalho, ou ainda mais simplesmente: a superação da sociedade das necessidades básicas foi impedida tanto por uma concepção limitada de necessidade quanto por uma prática corporativa dos interesses privados do poder. Esgotou-se a sociedade socialista na própria monotonia de sua auto-reprodução, progressivamente sem sentido, sem interesse, sem objetivo, sem lógica. Nada a ser superado, nenhum 
sonho a ser conquistado, nenhum desafio de valor histórico... somente a cansativa e monótona rotina da reprodução cotidiana do corpo, para a grande maioria, e do poder, para alguns privilegiados.

Viabilizar uma sociedade sem futuro foi a tarefa impossível da burocracia socialista. A primeira exigência foi o estabelecimento das fronteiras geográficas enquanto fronteiras absolutas: a construção-manutenção do socialismo dependeu do seu isolamento do mundo capitalista ocidental. Não eram somente suas leis econômicas que destruiriam a lógica da produção socialista, mas também seus padrões de comportamento social, que admitem os interesses individuais mesmo em detrimento dos interesses coletivos, É sua cultura consumista, excludente e alienadora que fundamenta a sociedade ocidental. Uma cultura de fácil penetração e de elevado grau de irracionalidade social, mas dotada da racionalidade da maximização dos interesses individuais em lugar dos coletivos.

\section{A NOVA CONFIGURAÇĀO DO SOCIALISMO INTERNACIONALE O FIM DA ALEMANHA ORIENTAL}

A identificação do coletivo com o socialismo foi inexistente em grande parte dos países que o adotaram. Polônia, Hungria, Checoslováquia, Iugoslávia, Bulgária, Romênia, Afeganistão, Albânia, Alemanha oriental, foram socialistas de efeito, não de causa. Expressaram a reorganização geo-política mundial do pós-guerra no fundamento do conflito EUA/URSS.

Mesmo na antiga URSS, as várias repúblicas foram submetidas ao socialismo, sem que suas particularidades histórico-culturais fossem consideradas. Depois da $2^{\mathrm{a}}$ Guerra Mundial, do COMECON e do Pacto de Varsóvia, os vários países socialistas adotaram o centralismo demo(buro)crático estalinista como metodologia política e policial. As orientações de Moscou não eram objeto de discussão, mas de implementação. Nem a tentativa de Kruschow de reorganização dos parâmetros metodológicos-práticos do socialismo supera a estrutura estalinista pré-definida, que perdurará até Gorbatschow.

A capacidade de gerir administrativa-burocraticamente sociedades 
progressivamente complexas é uma tarefa historicamente limitada. Não somente as necessidades sociais-materiais são progressivas, mas também as necessidades políticas, morais, éticas e culturais exigem novas construções histórico-sociais. São as exigências da reprodução do corpo e as do espírito que determinam limites históricos às formações sociais que são incapazes de representar as novas realidades sociais. Por períodos até longos é possível reproduzir-se a contradição destas necessidades inerentes ao espírito humano $e$ as estruturas do poder reacionário e tradicional. A força militar torna-se o principal argumento da negação das transformações sociais, mesmo quando estas mesmas não estão sequer sendo conscientemente reivindicadas pelas organizações sociais em questão.

$\mathrm{Na}$ URSS, mais precisamente na Rússia, tais contradições existiam reprimidas à 70 anos e, mesmo quando foram questionadas, o agente histórico fundamental não foi coletivo mas individual. Isso não significa que a sociedade não desempenha nenhum papel na construção-evolução histórica, mas foi imprescindivel que as vozes do poder e de poder representassem as latentes aspirações sociais.

Somente quando a concepção estalinista tradicional não sustentava mais a hegemonia do poder no interior da própria URSS, as contradições reprimidas em quase meio século explodem em praticamente todos os paises socialistas do leste europeu, redefinindo suas estruturas internas de poder.

Numa inversão da evolução histórica presumivel, confrontaram-se movimentos organizados pela liberdade e democratização do socialismo e com os agnupamentos casuais de individuos interessados em abandonar a RDA.

Na Alemanha oriental, as passeatas de Dresden, Leipzig ou de Berlim Oriental não exigiam inicialmente o fim da República Federal da Alemanha ou mesmo do socialismo ${ }^{8}$. A reivindicação, por si só revolucionária, limitava-se à democracia e liberdade. $O$ refrão nacional

${ }^{8}$ Há anos não se considerava prioritária a discussão relativa à reunificação das Alemanhas. Tanto ocidentais quanto orientais consideravam a existência dos dois Estados fato histórico irreversível. 
"o povo somos nós" (Wir sind das Volk) não encontrou resistência possivel diante das paralisadas forças políticas tradicionais do SED, já sem a histórica direção internacional do Büro soviético. $\mathrm{Na}$ medida em que a repressão foi ineficiente, surgiram outros interesses manifestados também nos slogans das passeatas: Nas ruas de Berlim ouvia-se o coro daqueles que manifestavam seu desejo de ir embora (Wir wollen raus). Outros ainda alimentavam suas esperanças na reestruturação democrática do socialismo, afirmando a intenção de permanecer: "nós ficamos aqui" (Wir bleiben hier). $\mathbf{O}$ desejo do consumismo (em lugar do comunismo) foi manifesto pelas expressões relativas ao Marco alemão ocidental: "vem o marco alemão, nós ficamos. Não vem, nós vamos até ele". (Kommt die D-Mark, bleiben wir. Kommt sie nicht, geh'n wir zu $i h r$ ). Esta era a concepção ideológica mais expressiva do denominado "movimento das massas" do leste alemão. Não uma luta social contra o socialismo ou contra a repressão, mas uma luta pelo consumismo de padrão ocidental. A ilusão da nova moeda fazia-os crer que a unificação monetária traria os beneficios do ocidente, sem qualquer custo social, sem os efeitos negativos da lógica de uma sociedade capitalista: sem riscos ao pleno emprego, com paridade salarial, baixos custos de habitação, transportes, escolas, etc. Foi a ilusão da possibilidade de manutenção de todos os beneficios sociais conquistados numa experiência histórica socialista, sob a nova perspectiva capitalista de reprodução social.

Por este motivo as formas da expressão social crítica não obtiveram uma conotação transformadora, de caráter revolucionário. Caracterizaram-se por uma postura individualista, na evasão de massas de cidadãos orientais em direção à República Federal da Alemanha ${ }^{9}$. As fronteiras abertas da Hungria e Checoslovaquia transformaram-se nos corredores preferenciais dos alemães orientais em fuga. Ou a RDA fechava suas fronteiras em definitivo inclusive com o mundo ainda socialista ou os países socialistas de fronteira com a Áustria e a RFA atendiam às solicitações de controle rigoroso destas fronteiras, evitando

${ }^{9}$ Segundo a Constituição da RFA, todos os cidadãos da RDA tinham cidadania automática na RFA. 
a fuga dos alemães orientais.

Muitos analistas políticos identificaram este movimento migratório como sendo um movimento político de resistência à repressão e à opressão do sistema comunista. Representou no entanto um dos maiores movimentos expontâneos de indivíduos isolados, apegados aos seus interesses privados e egoístas, de abandonar o socialismo alemão oriental em busca de vantagens pessoais. Em vários casos, homens abandonaram suas mulheres e crianças, mulheres seus maridos e filhos, adolescentes seus pais e amigos. Todos numa tentativa enlouquecida de fuga, empilhados nas embaixadas da Alemanha ocidental e da Áustria na Hungria e Checoslovaquia. Deixavam tudo para traz: casas, bens pessoais, empregos, escolas, familiares, amigos. Negavam e renegavam sua própria história.

$\mathrm{Na}$ tentativa de evitar a desintegração da RDA, o SED recomenda a abertura das fronteiras diretas com a RFA. A expectativa com as autorizações de viagem era que os habitantes da RDA retornassem à pátria tão logo tivessem sanadas suas curiosidades ocidentais.

Nem a RDA nem a RFA sustentariam processos emigratórios e imigratórios, respectivamente, de alta dimensão. $O$ processo da reunificação, já fora da pauta das discussões políticas em ambos os lados, surpreendeu não somente o mundo, mas os próprios alemães orientais e ocidentais. No calor emocional das expectativas transformadoras, poucas foram as vozes racionais na discussão do processo. Unificar tornou-se decisão de cúpula antes de ter sido exigência real das "bases". Uma casualidade histórica sem precedentes na História.

A alternativa eleitoral já indicava a dimensão das dificuldades na manutenção do próprio sistema socialista. Mas não eram suficientes à ansiedade dos políticos e de alguns setores da própria sociedade. Medidas populistas são adotadas afim de estabelecer a tranqüilidade política interna, mas sem êxito real. Apesar da queda do muro de Berlim (nov/89), $343 \mathrm{mil}$ cidadãos da Alemanha oriental emigraram para 0 ocidente. Outros 3 milhões tencionavam abandonar a RDA por desconfianças no governo Modrow. Nem a RDA poderia perder sua força de trabalho nem a RFA teria como absorver 3 milhôes de novos cida- 
dãos em busca de casas, empregos, escolas, etc. ${ }^{10} \mathrm{~A}$ unificação tomava-se questão vital para ambas as partes e o processo de democratização interna o seu instrumento principal.

Pela primeira vez na história da RDA, e após 57 anos, são realizadas no dia 18 de março de 1990 eleições livres em território alemão oriental.

O CDU, DSU e DA (Demokratischer Aufbruch) formaram a Aliança pela Alemanha e prometiam acelerar a integração, utilizando o apoio de Helmut Kohl e de frases de efeito, como "bem-estar social em lugar de socialismo" ("Wohlstand statt Sozialismus"). A Aliança pela Alemanha vence as eleições com base na plataforma da reunificação. De Mazière é eleito e Bonn passa a governar a RDA. A Alemanha oriental torna-se troféu da guerra fria mesmo antes da reunificação, permitindo uma revitalização política do Chanceler Kohl e seu CDU. Segundo Christa Luft, 1990 foi o ano dos políticos e não dos economistas. ${ }^{11}$

A reunificação passou a ser plataforma de campanha para todos os demais partidos, com diferenças em calendários e táticas, mas sempre na perspectiva da inclusão da RDA do lado ocidental do mundo.

Até o SPD fundamentava sua campanha eleitoral na promessa de trazer o D-Mark tão rápido quanto possivel. Mas as coalisões sociais democratas não tiveram chances. A tendência de negar todo o passado estava pré-determinada e os cidadãos orientais acreditavam ter de apoiar o partido de Kohl se quisessem uma reunificação rápida e segura. Foi rápida, mas não tão segura quanto pretendiam seus interessados.

\section{O PROCESSO DA UNIFICAÇÃO E DESESTATIZAÇÃO DA ALEMANHA ORIENTAL O CASO TREUHAND}

Desde sua criação a Treuhandanstalt foi um enigma para seus

\footnotetext{
${ }^{10}$ Vide Christ, Peter. Neubauer, Ralf. Kolonie im eigenen Land, p. 66. Rowohlt Berlin. 1991.

11 "1990 war ein Jahr der Politiker, nicht der Oekonomen". Christa Luft. In: Wolfgang Seibel. Treuhandanstalt: Das Unmögliche wagen. p. 111.
} 
próprios criadores: alguns a entendiam como um meio para construir um novo socialismo, sem uma direção centralizada e com elementos de economia de mercado, mas sob a garantia da manutenção dos princípios socialistas e da socialização dos meios de produção. Outros a queriam utilizar na construção de uma economia de mercado com princípios sociais e ecológicos. Alguns pretendiam, através dela, construir uma terceira via entre o capitalismo e o socialismo. ${ }^{12}$

Além de politicamente delicada, a situação econômica da RDA indicava a aproximação de uma catástrofe no padrão de vida dos alemães orientais. Somente em 1990, com a finalidade de evitar o agravamento do endividamento externo, o padrão de vida (Lebensstandard) dos alemães orientais seria reduzido de 25 a $30 \%$. A situação caótica exigia auxílio externo ocidental afim de garantir uma possibilidade de estabilização interna da economia.

A necessidade urgente da reforma econômica, associada ao movimento político interno e às pressões externas, exigia a transformação da economia planificada em economia de mercado, que, segundo o projeto de Modrow, deveria efetivar-se somente no início de 1993. A base desta transformação seria, evidentemente, a venda de empresas estatais a capitais estrangeiros, embora limitada até um percentual de $49 \%$, como sugeria Modrow.

Entre as alternativas à privatização do patrimônio público se apresentava a criação de uma bolsa de valores, através da qual seriam vendidas num prazo de 5 anos as ações das empresas estatais. Nas discussões iniciais chegou-se inclusive a propor-se a distribuição da propriedade estatal ao conjunto dos cidadãos da RDA. A transformação das empresas estatais em companhias por ações seria comandada por uma nova e independente instituição - Treuhandanstalt - com autonomia para vender as companhias que considerasse conveniente, liquidá-las ou saneá-las de acordo com sua exclusiva avaliação. Obviamente na condição de representante da propriedade do povo e não na condi-

${ }^{12}$ Wolfram Fischer und Harm Schroeter. Die Entstehung der Treuhandanstalt. In: Treuhandanstalt: Das Unmögliche Wagen. Akademie Verlag. Berlin. 1993. p. 18. 
ção de ser, ela mesma, proprietária dos bens da RDA. A concepção do governo Modrow permanecia na perspectiva das reformas pela construção de um socialismo melhor. Estas concepçães tiveram espaço progressivamente reduzido, conforme aproximavam-se as eleições diretas na RDA.

A derrota política de Modrow expressava, no seu oposto, a vitória do imediatismo de alguns setores políticos. Aliados ao governo de Bonn, as bases políticas de De Mazière anteciparam eleições, venceram-nas e, sugerindo a impossibilidade de administrar um caos econômico, resultado de 40 anos de socialismo, defendiam tanto a privatização quanto a unificação imediata com a Alemanha Ocidental, reproduzindo com fidelidade servil as intenções do governo de Bonn que havia decidido, em meados de fevereiro de 1990 , pela reunificação no mais curto espaço de tempo possível.

A criação da Treuhand em 15.03.1990 foi o primeiro passo ao retorno capitalista.

Com a unificação monetária prevista para julho, a Treuhand havia sido incumbida da tarefa de mapear e transformar em sociedades por ações as $8 \mathrm{mil}$ empresas estatais da RDA. Mesmo assim, até a data da unificação monetária haviam sido transformadas 3.600 empresas estatais em empresas por ações.

Algumas análises provenientes da própria Treunhand eram confusas, no que se referia à capacidade produtiva das empresas orientais. Segundo Fischer, nas primeiras avaliações somente $30 \%$ das empresas orientais poderiam manter-se ativas após a unificação monetária. $50 \%$ poderiam atingir este nível concorrencial após um processo de saneamento. $20 \%$ não teriam qualquer chance de tornarem-se produtivas. 2 meses depois, $40 \%$ das empresas eram consideradas com nivel de produtividade suficiente para suportarem a concorrência ocidental, $30 \%$ necessitavam ser saneadas para atingir este nível e $40 \%$ eram consideradas irrecuperáveis. ${ }^{13}$

${ }^{13}$ Vide Wolfram Fischer, op. cit. p. 31 . 
Apesar das imprecisões, o processo era impulsionado pela política. Foi relativamente consensual transferir as responsabilidades pela caótica situação da RDA ao Estado burocratizado e ao modelo socialista da produção de riqueza.

De acordo com o balanço oficial de 1989 , o patrimônio alemão oriental equivaleria a aproximadamente 900 bilhões de Marcos, nas avaliações dos representantes da RDA. Para os técnicos ocidentais não ultrapassariam 250 bilhões de DM. Em termos absolutos não haviam dúvidas em relação à concentração da propriedade estatal. Em empresas industriais foram computadas mais de 8.000; lojas comerciais, $25.000 ; 7.500$ restaurantes e hotéis; 2.000 farmácias; 900 livrarias; 1,7 milhão de $\mathrm{Ha}$ de terras produtivas; milhões de metros quadrados de imóveis rurais e urbanos; 4 milhões de trabalhadores e 16 milhões de habitantes. Todos considerados, em princípio, proprietários coletivos (na qualidade de cidadãos da RDA), que perdem uma propriedade real por nunca ter sido formal e individual.

O processo de articulação-estruturação da Treuhand inicia-se com Detlev Kasten Rohwedder como presidente e com Jenas Odewald na presidência do Conselho de Administração, logo após a breve passagem de Rainer Maria Gohlke - até então presidente do "Deutschen Bundesbahn"14 - pela presidência da Instituição. Segundo Seibel, a breve era Gohlte expressava as incertezas em relação às funções institucionais. Era considerada nesta época - julho e agosto de 1990 - uma organização virtual, pois inexistiam estruturas jurídicas para orientar a reorganização das empresas em sociedades por ações. A própria Treuhand era uma incógnita em si mesma. ${ }^{15}$ Com Rohwedder na presidência, o dinamismo torna-se característico na instituição. Evidente que um dinamismo direcionado aos interesses ocidentais. A privatização haveria de ser a razão de existência da Treuhand.

Enquanto instrumento ocidental, a Treuhandanstalt deveria ser a instituição condutora do processo de saneamento, privatização ou li-

\footnotetext{
${ }^{14}$ Rede Ferroviária Alemã.

${ }^{15}$ Wolfgang Seibel. Organisatorische Entwicklung. p. 116.
} 
quidação das empresas do Estado alemão oriental. Sua equipe era constituída basicamente por representantes do capital privado da Alemanha ocidental. Não os funcionários do Estado de Bonn ou de Berlim oriental, mas importantes Managers do capital privado ocidental por sua inquestionóvel capacidade de organização empresarial na perspectiva da lógica mercantil e eficiência do capital foram os responsáveis pelo processo como um todo. Se por um lado as diretrizes do processo exigiam pessoal com experiência no mundo das leis do mercado, as empresas privadas (ocidentais) também consideraram conveniente ceder seus quadros para o processo da privatização das empresas orientais $^{16}$.

Como caso único na história do mundo - a Treuhandanstalt tornou-se, da noite para o dia a maior holding do mundo ${ }^{17}$, era de imaginar-se um conjunto de dificuldades e incertezas nas políticas concretas do processo de privatização, saneamento e liquidação. A atual presidente da Treuhand, Birgit Breuel, afirmou que em 1990 não havia nenhuma expectativa, nenhuma concepção teórica elaborada que permitisse aos próprios membros da Treuhand uma clareza de suas funçóes ${ }^{18}$. A alternativa econômica estabelecida foi extremamente simplista. Vender tudo o que fosse possível, a qualquer preço. Fechar tudo o que não fosse vendável, a qualquer custo. Neste simplismo foi considerado o capitalismo na exclusiva perspectiva dos mercados livres e da propriedade privada. Privatizar a propriedade estatal e liberar as forças reprimidas da acumulação capitalista eram elementos considerados suficientes para construir no território da RDA o mesmo padrão de vida existente no lado ocidental. Através dos discursos alimentavam-se as expectativas de tantos ale-

16 "Nach der Wiedervereinigung wurde deshalb der Treuhandanstalt in starkem Masse westdeutsches Management zugeführt, sowohl auf der Ebene des Vorstands als auch auf der der Branchendirektorate und der 15 regionalen Niederlassungen". Jürgen Müller. Auswirkungen der Privatisierung. p. 385.

17 "Es gibt keine historische Parallele für eine auch nur annähernd vergleichbare Anhäufung wirtschaftlicher Macht unter einem Dach. Die Treuhandanstalt war gleichsam über Nacht zur größten Wirtschaftsholding der Welt geworden". (Peter Christ, Ralf Neubauer. Kolonie im eigenen Land. p. 122.).

${ }^{18}$ Breuel,Birgit. Entrevista ao Berliner Zeitung de 18.12.1993. 
mães que esperavam o novo tempo, o tempo em que o estado capitalista do bem-estar social viesse substituir o socialismo das necessidades sociais.

Nesta lógica, com as expectativas sociais de um lado e os interesses dos capitais privados do ocidente de outro, deu-se inicio ao maior leilão da história do mundo. Bilhões de marcos alemães teriam sido necessários para transferir a propriedade estatal para as mãos privadas. Bilhões de marcos que nunca existiram. Nem o Estado alemão ocidental, com sua terceira maior economia do mundo, poderia candidatar-se à compra dos bens dos alemães orientais ou mesmo financiar tal processo pela simples inexistência de recursos financeiros. Algum milagre deveria ser providenciado, pois o Estado passaria a assumir um conjunto de encargos sociais com mais 16 milhões de cidadãos.

A questão central é que os interesses das unidades de capital ocidental não estavam necessariamente voltadas ao capital produtivo existente no lado oriental, mas ao latente mercado consumidor interno e extemo, absorvendo o mercado do leste europeu abastecido até então por empresas da RDA. O capital produtivo em sî somente atrairia o capital ocidental na possibilidade concreta do lucro. Do contrário, sua aquisição é antes a eliminação da concorrência potencial representada pela possível modernização patrocinada por capitais internacionais. Além disso, muitos investidores pretendiam a simples posse do patrimônio imobiliário das empresas do setor oriental, não interessando sua potencialidade industrial.

A primeira grande privatização patrocinada pela Treuhand já indicava as bases relativamente deficientes de sua própria organização interna. Sem uma estrutura definida, tomou-se rapidamente instrumento dos capitais privados da Alemanha Ocidental. A privatização do Interhotel $A G$, com 34 hotéis na RDA, foi resultado de um contrato direto entre a Treuhand e a Steinberger GmbH - empresa ocidental -, em condições desfavoráveis à Treuhand ${ }^{19}$. Seguiu-se a esta, práticas

${ }^{19}$ Vide Wolfgang Seibel. Die organisatorische Entwicklung der Treuhandanstalt. In: Treuhandanstalt: Das Unmögliche wagen. Akademie Verlag. Berlin. 1993, p. 114. 
semelhantes para vários casos de privatização.

Combinados os interesses dos agentes da Treuhand e os interesses dos capitais privados ocidentais, empresas com valores patrimoniais de 200 milhões de DM foram vendidas a empresários por valores simbólicos de 1,00 DM. Ou no exemplo concreto da fábrica de filmes Wolfen, que possuía um preço de venda negativo de 120 milhões de marcos alemães, que auxiliariam os novos proprietários nos investimentos necessários à manutenção das atividades produtivas da empresa. Segundo a Treuhand, tais negociações se justificariam devido ao fato de tais empresas serem tão improdutivas e inviáveis no mercado capitalista, que sua sobrevivência (preservando empregos de milhares de alemães orientais) implicaria em investimentos superiores aos valores patrimoniais fictícios.

Esta concepção encontra muitos argumentos favoráveis. Segundo Mueller, as privatizações não são de imediato independentes das antigas relações de trabalho e composição do capital. Para muitas empresas, os preços necessitam ser baixos, considerados as antigas dívidas; responsabilidades com meio ambiente e obrigações sociais. Diz ainda o autor que para muitas empresas, o risco de viabilidade econômica seriam tão elevados que somente a preços simbólicos seriam encontrados interessados. Um outro fator complementar foi a já existente estrutura industrial do ocidente alemão e europeu, que reduzia as possibilidades de investimentos produtivos em empresas da Alemanha oriental sem riscos elevados. Somente com preços atraentemente baixos encontrar-se-íam investidores dispostos na aquisição de complexos industriais defasados tecnologicamente. ${ }^{20}$

Nos parece evidente que, sob o prisma da lógica capitalista, não haviam alternativas aos processos reais que se verificaram. Os interesses dos setores privados do capital mantinham de uma forma bastante intima o controle político do processo de transformações no oriente, especialmente pela urgência com que os próprios alemães orientais exigiam o processo da reunificação. São corretos os argumentos relativos às taxas de valorização do capital na RDA, às dívidas acumuladas,

${ }^{20}$ Jürgen Müller. Auswirkung der Privatisierung. Vide pp. 390-391. 
às necessidades de volumosos investimentos na construção de uma capacidade produtiva competitiva, ao atraso tecnológico, ao excesso de mão-de-obra nas fábricas, etc. Neste sentido explicar-se-íam muitas das vendas por valores simbólicos $(1,00 \mathrm{DM})$ e também muitas das liquidações patrocinadas pela Treuhand.

Por outro lado, é irônica a suposição que tais procedimentos tenham-se baseado na exclusividade dos ditames do mercado. Os casos de corrupção, servilismo, clientelismo, lobbismo, etc., comprovam que as privatizações ocorridas não expressavam um procedimento puramente capitalista. Somente os casos associados ao período de Rohwedder já seriam suficientes para questionar a metodologia das privatizações. Além de presidente da Hoesch AG, foi também membro do Conselho Fiscal (Aufsichtsrat) da IBM, Volvo, da Allianz-Versicherung e da Ruhrgas-AG. Nas primeiras privatizações, por uma certa coincidência, a Allianz assume o sistema completo da seguridade social (estatal) da RDA e a Ruhrgas-AG apropria-se de um dos mais lucrativos setores da economia da parte oriental: a Ferngasnetz. ${ }^{21}$ Outros casos, como o da Geräte- und Reglerwerke Teltow, vendida ao empresário Claus Wisser pelo valor simbólico de 1,00 DM, é também um dos muitos exemplos a desautorizar a versão oficial oferecida pela Treuhand, pelo governo de Bonn e pelo conjunto de empresários, políticos e teóricos que defenderam o processo no seu todo. Die Markische Baustoff-Service GmbH, die Firma Mettalbau Technikinstandsetzungsund Handels GmbH, die Elektrowerke Egeln, Narva-Betriebe e tantos outros foram exemplos de negociações pouco éticas. Foi confirmandose, no estudo dos casos, que a maior parte do patrimônio da RDA foi transferido à compradores pouco interessados em atividades produtivas, mas à atividades especulativas. A especulação mais atraente foi sobre a propriedade imobiliária, que além de investimento sem risco, garantia a possibilidade de lucros de milhões de DM sem qualquer investimento real.

É também parcialmente verdadeira a afirmação que justifica a exclusividade ocidental na compra do capital da RDA pela falta de 
capital acumulado pelos cidadãos orientais. Mesmo considerado uma virtual existência de tal capital, a Treuhand teria encontrado então outras alternativas que priorizassem os interesses do capital alemão ocidental. Uma destas alternativas foi a inclusão legal do pré-requisito "experiência comprovada em assuntos de mercado" para os interessados na aquisição de empréstimos bancários para a compra de empresas estatais. Este requisito impedia que os diretores e o quadro de funcionários de uma empresa da RDA obtivessem empréstimos bancários para uma transação de compra. Para os bancos, a concessão de empréstimos estaria condicionada exclusivamente ao patrimônio hipotecado. Cada empresa a ser privatizada possuía patrimônio imobiliário suficiente para garantir a obtenção de créditos financeiros. A força da lei, no entanto, impedia que os "inexperientes" se candidatassem diante da toda poderosa Treuhandanstalt, tendo ou não recursos financeiros suficientes para tal.

Outros casos verificaram-se diante do interesse de algumas empresas estrangeiras na aquisição de complexos inteiros ou parte deles para investimento em território alemão. Algumas foram alijadas na obscuridade do processo, pois a presença de empresas internacionais, adquirindo indústrias no interior da própria Alemanha é mais grave que a concorrência tradicional, pois perdem-se alguns mecanismos de controle e de garantia de reproduçâo e lucro das companhias nacionais, como taxas e impostos de importação, taxas de câmbio, etc., ao mesmo tempo que acirram-se as disputas pelo mercado interno.

Não tratava-se, portanto, somente de questões relativas a preços de venda ou nível de competitividade, mas especialmente de poder lobista, corporativo. É interessante lembrar que os 15 diretores das sucursais da Treuhand, assim como os cargos de direção na central de Berlim, eram ocupados por managers vindos diretamente de companhias da Alemanha Ocidental.

A questão que permanece, em função dos resultados concretos, é sempre a possibilidade da altemativa de um terceiro caminho. Uma questâo que tem pouco significado para a própria Alemanha em si mesma, pois não há retorno possível, mas é importante na avaliação das alternativas privatizantes noutros países, como o Brasil. 
Outros casos, contudo, mais obscuros que a opção políticoeconômica em si mesma, merecem avaliações mais precisas. É possivel que o dilema central não repousasse sequer na dicotomia do privatizarnão-privatizar. Possivelmente a privatização fosse uma alternativa adequada e correta do ponto de vista econômico. Mas um patrimônio de tal envergadura como é o patrimônio de um país que representava a $10^{\text {a }}$ força econômica do mundo, desperta evidentemente a cobiça e os interesses privados. Se os capitalistas ocidentais detinham o controle absoluto do processo de privatização, se os contratos de compra-venda eram secretos por razões de estratégia industrial, como diziam os membros da Treuhand e confirmavam os compradores, e, por esse mesmo motivo, não podiam ser discutidos pelos vários setores sociais interessados, havia pouca chance de ocorrer um processo legitimo de transformação da economia da RDA.

A particularidade de todo o processo da privatização do patrimônio da RDA explica-se basicamente na particularidade da reunificação com a Alemanha ocidental. Processos de privatização ocorrem em todos os países do mundo, mesmo nos mais desenvolvidos. No caso das economias socialistas, que guardam semelhanças com a RDA, houve também escandalosos casos envolvendo capitais internacionais e burocracia corrupta. Mesmo assim, não promoveu-se em nenhum destes países uma devastação dos denominados patrimônios do povo como na RDA.

\section{OS RESULTADOS DA LÓGICA CAPITALISTA NO EXMUNDO SOCIALISTA DA RDA}

A complexidade da reunificação alemã não tem paralelos na história do mundo. A decisão de unificar foi basicamente política. A forma foi definida por uma concepção geral de teoria econômica, aparentemente pela teoria neoliberal. Devido à ação irresponsável e burocratizada do Estado e à falta de um mercado livre, estabeleceu-se um tipo de economia (e sociedade) estranguladora do desenvolvimento econômico (e social). Como alternativa, a teoria neoliberal sugere a liberação completa destas barreiras representadas pelo Estado. 
Compreendida no seu campo teórico-científico, a teoria neoliberal pode ser criticada pela falta de coerência histórica, teórica e prática. Mas não é o caso para se compreender-explicar as orientações políticas da Treuhandanstalt no cașo das empresas do leste alemão. Aliás, na maioria dos casos (considerando-se políticas estatais modernas em vários países do mundo), não é sequer necessário adentrar no debate teórico com a concepção neoliberal.

$O$ determinante na concepção da Treuhand não foram as vantagens do mercado no desenvolvimento sócio-econômico, mas os interesses dos capitais privados do lado alemão ocidental. Não houve um debate político ou teórico para elaborar uma metodologia adequada à reunificação, mas uma pré-definição dos representantes do governo, que representavam os interesses dos capitais privados ocidentais. A cúpula da Treuhand foi a cúpula do capital privado. Sequer representantes do governo de Bonn foram chamados à participar da nova instituição. Com absoluta exclusividade, foram os empresários a definir a política econômica para os 5 novos estados da Alemanha. Nem os partidos políticos, nem o governo ou as organizações sindicais tiveram alguma chance de influir na condução do processo.

Esta autonomia absoluta concedida à Treuhand, ou conquistada pelos capitais privados, na condução do processo de integração econômica (por conseguinte social e também política) resultaria, como é óbvio, numa definição limitada de prioridades. Tão limitada que os custos sociais para o próprio Estado não foram considerados e optou-se pela venda de tudo o que fosse possível, o mais breve possível e pelo preço possível, liquidando o restante considerado irrecuperável. Evidentemente que não por caso imprevisto nem por falha teórico-analítica, resulta numa catástrofe.

Sem o Estado para avaliar os impactos globais de políticas econômicas e propor paliativos temporários que garantam a sua viabilidade, é impossível considerar que haja um mercado interessado e disposto a compensar as irresponsabilidades das experiências teóricas.

O ufanismo da vitória da guerra fria, depois de 4 décadas de conflitos Leste-Oeste, cede lugar à realidade concreta do processo da 
reunificação, respeitando os fundamentos básicos das economias de mercado.

Evidentemente que as possibilidades de integração direta da economia da Alemanha oriental na comunidade européia eliminaria qualquer chance de sobrevivência de seu parque industrial, devido os baixos níveis de produtividade. Neste aspecto foi sempre óbvia a constatação de seu nível produtivo e competitivo inferior às indústrias do ocidente. Em alguns setores, a indústria do leste não obtinha sequer $30 \%$ da capacidade produtiva das suas correspondentes ocidentais.

Improdutividade, no caso da RDA, deve ser mensurada através de seus próprios exemplos: o consórcio VEB-Mansfeld Kombinat Wilhem Pieck extraía a tonelada de cobre a um custo de 47.000,00 RDA-M (ou DM após a unificação monetária), enquanto no mercado internacional seu preço variava entre $3.500,00$ e 4.000,00 DM. De todo o complexo empresarial com 48 mil funcionários restaram 8 mil. As fábricas de automóveis Trabant, em Zwickau, e Wartburg, em Eisenach, foram obrigadas a fechar suas portas por terem custos de produção de 8.000,00 DM e 14.400,00 DM respectivamente, extremamente elevados se consideradas as qualidades dos referidos automóveis e as ofertas dos concorrentes alemães e japoneses. Somente a Wartburg, para manter suas linhas de montagem em funcionamento e colocar no mercado um automóvel com preço competitivo, necessitaria de subsídios de 100 milhões de DM para cada $15 \mathrm{mil}$ carros (ou aproximadamente $7 \mathrm{mil}$ DM por carro). No setor de eletrônica e computação a situação era também catastrófica, só comparada com China ou Índia. Evidente que, em termos de alta tecnologia, poucos são os países no mundo com razoável potencial competitivo. $\mathrm{O}$ atraso da RDA nesta área correspondia a periodos variáveis de 10 a 20 anos.

As especializações generalizadas no leste europeu serviam como incentivo negativo à evolução das forças produtivas. Sem concorrência e com mercados nacionais e internacionais garantidos, pouco aplicavase em modernização tecnológica. Indústrias óticas de Rathenow abasteciam o mercado do leste europeu em parceria com outras óticas de Jena. Liquidadas por não possuírem nem competitividade nem possibilidade de tomarem-se competitivas diante das modernas concorrentes 
da Alemanha ocidental, produziram alguns desertos industriais na retaguarda da reunificação. Em muitas destas cidades especializadas na produção de um único produto, a força de trabalho foi obrigada a migrar, restando uma população de trabalhadores mais velhos, induzidos à aposentadoria prematura.

Por outro lado, a reunificação das Alemanhas, pelo valor relativo do marco alemão e pelos parấmetros da produtividade ocidental, transformaram os produtos provenientes do leste europeu em mercadorias sem atrativos (nem financeiros, nem qualitativos) anulando a possibilidade de manutenção dos antigos contratos comerciais entre o COMECON e a ex-RDA.

Extinta a "paridade rublo", não haviam mais os elementos solidariedade e ideologia para regular as trocas internacionais entre os antigos parceiros. As moedas internacionais fortes especialmente o dólar - passaram as ser determinantes nos processos de troca e os fundamentos da produtividade e competitividade fundamentais na escolha de fornecedores e clientes. Os déficits comerciais dos países do leste com a antiga e solidária parceira ultrapassaram 21 bilhões de marcos alemães (15 biIhões com a Rússia e 6 bilhões com os demais) e foram suspensas praticamente todas as importações da RDA. Entre 1989 e 1993, as exportações da ex-RDA ao leste europeu reduziram-se de 29 bilhões para 7 bilhões de $\operatorname{marcos}{ }^{22}$.

A inviabilidade comercial tomou-se mais um elemento do desemprego progressivo, como demonstram os incontáveis exemplos disponiveis. A indústria têxtil de Cottbus empregava 8.000 trabalhadores antes da unificação e restaram $600 . \mathrm{Na}$ fábrica de semicondutores de Frankfurt/Oder trabalhavam outros 8.000 , restando 300 funcionários no setor de microeletrônica. No complexo de microeletrônica de Teltow trabalhavam 10.000 empregados. Restam atualmente 150 pessoas temporariamente ocupadas.

22 "Seit 1989 hat der Export von Ostdeutschland nach Osteuropa einen Rückgang von 29 Milliarden DM auf 7 Milliarden DM zu verzeichnen". Pohl, Hans-Georg. In TreuhandInformation, 20.01.94. p. 26. 
Noventa por cento das mulheres tinham emprego nos tempos da RDA. Atualmente menos de $50 \%$ conseguiram mantê-los ou obter algum substituto. Trabalhadores com mais de 55 anos estão induzidos às aposentadorias prematuras por não terem mais possibilidades de encontrarem trabalho. O mais grave é que tais aposentadorias são calculadas em $65 \%$ dos últimos rendimentos, contabilizados em RDA-Mark, que, transformados em D-Mark, tem valor relativo ainda menor ${ }^{23}$.

Alguns teóricos alemães analisaram o processo da reunificação e seus resultados como condição necessária à superação dos limites e obstáculos do desenvolvimento econômico e social. Müller afirma que o resultadio da reunificação foi um enorme retrocesso na produção $e$ ocupação em todas as atividades empresariais da RDA. Até meados de 1993, 80\% dos postos de trabalho foram desativados. ${ }^{24}$ Apesar disso, conclui o mesmo autor com uma apologia do sucesso dolorido, sempre considerando as condições macroeconômicas do processo e não as condições sociais da adaptação ao mercado capitalista.

Outros são mais rígidos, talvez mais sensatos quanto ao sucesso, mesmo que dolorido. Dieter Kampe, afirma que a base industrial da Alemanha oriental não sobreviveu ao regime da Treuhand. $O$ número de ocupações nós setores industriais clássicos nos novos estados reduziu-se aproximadamente em $75 \%$, de 3,2 milhões para aproximadamente 700 mil de ocupações. ${ }^{25}$ Já no início de 1991, Rohwedder emitia uma circular interna afirmando que a decisão de eliminar empregos é dolorosa para os atingidos, mas mantê-los seria onerosa para a sociedade em seu conjunto e retardaria a reconstrução econômica da região oriental da Alemanha. ${ }^{26}$ Um processo tão violento que produziu, já em junho de 1990, o primeiro milhão de desempregados. Daí em diante,

${ }^{23}$ Vide Regine Hildebrandt. "Wir werden ein Volk von Rentner sein". In: Die Treuhand und die zweite Enteignung der Ostdeutschen. Ed. Spangenberg. p. 76.

${ }^{24}$ Jürgen Müller. Op. cit. p. 406.

${ }^{25}$ Dieter Kampe. Wer uns kennenlernt, gewinnt uns lieb. Nachruf über die Treuhand. Rotbuch Verlag. pp. 188-189.

${ }^{26}$ Detlev Rohwedder. Dokument der Treuhandanstalt. 27.03.1991. In Martin Flug. Treuhand-Poker. op.cit. p.193. 
acresceram-se progressivamente outros e outros tantos.

A proposta oficial sugeria a necessidade de destruição das viciadas e incompativeis relações de trabalho e produção de fundamentos socialistas num primeiro momento, para permitir sua reconstrução posterior, na lógica da economia de mercado. No entanto, é relativamente consensual que as possibilidades de sucesso de políticas regionais de desenvolvimento são relativamente nulas. Os exemplos podem ser verificados em todo o mundo. Dos países ricos aos pobres. $\mathrm{Na}$ própria Alemanha, com o insucesso das suas políticas de modernização e desenvolvimento do norte, na Itália com as variadas tentativas de industrialização do sul ou no Brasil com as políticas de desenvolvimento regional do norte e nordeste. A tendência do capital é concentrar-se nas regiões mais dinâmicas. $\dot{E}$ nelas que as possibilidades de rentabilidade são efetivamente maiores e mais seguras. No caso da Alemanha, o conteúdo das propostas de política regional de desenvolvimento é basicamente político-ideológico. Tem o intuito de manter as esperanças e ilusões dos milhões de cidadãos incorporados recentemente à lógica capitalista da reprodução social.

Socialistas da geo-política do pós-guerra e surpreendidos pela reunificação passiva, os alemães orientais dispensaram novos experimentos históricos de massa. Negaram sua história socialista na perspectiva do bem-estar social capitalista. Encontraram-se num limbo sem passado e com futuro duvidoso. Sem retomo, alimenta-se ainda a expectativa que os desequilíbrios existentes não os caracterizem enquanto pólo de miséria frente à riqueza ocidental. Tudo o que parecia sólido desmanchou-se no ar. 